\title{
Supply chain management systems - A survey of the state-of-the-art
}

\author{
Philipp Schiegg, Robert Roesgen, Herwig Mittermayer, Volker Stich \\ Research Institute for Operations Management (FIR), Aachen University of Technology, \\ Pontdriesch 14/16, D - 52062 Aachen, Germany
}

\begin{abstract}
Recent developments in information and communication technology have motivated much of the interest in supply chain management (SCM). Today, a multitude of software providers offer solutions that support the integrated planning and control of inter-and crossorganisational supply chains, so called supply chain management systems. This paper investigates current trends in information systems for supply chain management. The authors present a model to systematically describe supply chain management activities. A survey among providers of SCM systems presents details about the performance of currently available SCM systems, different system philosophies, as well as their prevalence in different industries.
\end{abstract}

Keywords

Supply Chain Management, SCM System, Software Market Analysis.

\section{DEFINITIONS AND CONCEPTS}

The term supply chain management ( $\mathrm{SCM}$ ) is fairly new in the literature, appearing first in the early 1980's. Since then, practitioners and educators have addressed the concept of SCM either as an extension of logistics, the same as logistics, or as a comprehensive approach for business integration [1,2]. Although there is no clear definition of SCM and its differentiation from logistics to date, a review of the literature and numerous case studies indicate certain commonalties and a new emerging understanding of SCM [2]:

Supply chain management is a logical progression of logistics management. The Council of Logistics Management (CLM) defines logistics as a part of supply chain management: "Logistics is part of the supply chain process that plans, implements, and controls the efficient, cost-effective flow and storage of goods, services, and related information from the point-of-origin to the point-of-consumption in order to meet customers' requirements [3]". Supply chain management extends the definition of logistics management by aiming at integrating and managing all business processes across the supply chain. In this sense, supply chain management "transcends firms, functions, and business processes [2]." New product development 
or customer relationship management are examples of such supply chain business processes.

Supply chain management develops through several stages of increasing intraand inter-organisational integration and coordination; in the broadest sense, the integration and coordination extends to the entire supply chain from its initial source (supplier's supplier) to the ultimate consumer (consumer's consumer). Supply chain management involves many autonomous and independent organisations. Accordingly, the management of intra- and inter-organisational relationships and business processes is of paramount importance for effective SCM. Supply chain management deals with the flow of goods, the flow of information, as well as the associated planning and control activities to ensure smooth operation of the supply chain. Despite the lack of a fundamental theoretical concept, business enterprises are aware of the importance of the supply chain they are operating in. In the last few years, it has become clear that many companies have reduced manufacturing costs as much as practically possible [4]. Those companies are now discovering the opportunities to capture hidden synergies that lie in their intricate network of business relationships [5], viewing SCM as the next step in order to increase profit and market share.

For this paper, the following definition of supply chain management is presented: "Supply chain management is the planning, controlling and monitoring of all procurement, production and distribution activities subject to material, time and capacity constraints." SCM as a managerial concept contains different approaches and tools. The focus of this paper lies on SCM-systems as an elementary basic for realizing the potentials of SCM. The The Research Institute for Operations Management (FIR) observes the market for SCM-systems, especially on the German market, and built up a database representing functionalities of most of the relevant SCM-systems. This paper shows up results of a recent survey carried out by FIR that identified different focuses of the systems. It was also possible to cluster the different vendors in categories.

\section{Information Systems for Supply Chain Management}

Recent developments in information and communication technology have motivated much of the interest in SCM. Information technology (IT) is an enabler and a key prerequisite for effective SCM. In order to plan, control and monitor all processes along the supply chain, a transparent flow of information throughout the supply chain and an integration of information systems has to be ensured. Based on the model of planning activities, one can systematically describe and standardise functionalities of currently available SCM systems. SCM systems are IT tools for the integrated, cross-organisational planning of supply chains.

Because of the multitude of varieties in strategic networks more and more systems are coming to market. These systems have different focuses and concentrate on different topics in their optimisation. So not only the number of systems, but also the variety and focuses of the systems emerge rapidly. Therefore the FIR developed a reference model the be able to assign different systems to different functionalities to be able to categorize the systems. Furthermore this reference model can be used as a help for companies searching for a convenient SCM-system. 


\section{REFERENCE MODEL FOR SUPPLY CHAIN PLANNING ACTIVITIES}

In the following, the authors present a reference model that provides a framework and orientation for planning activities in a supply chain context. It was developed by FIR and bases upon the experiences from diverse consulting projects and the market observation over the years. The activities represent different functionalities within SCM-systems in order to be able identify the different focuses of each system. This model represents all common functionalities of state-of-the-art SCM systems.

The model is build on two dimensions. On the one hand, planning activities in SCM can be divided into three different levels (see Figure 1): supply chain configuration, supply chain planning, and supply chain controlling. The different levels logically build upon each other. On the other hand, planning activities are characterised by the business process to which they pertain to: source, make, sell, deliver [6]. The reference model for supply chain planning activities is depicted in Figure 1). The time horizon of the planning activities vary from short-term, e.g. an hour or a day, mid-term, e.g. a day or a week, to long-term, a day, a month or even one or more years. In same cases, e.g. supply chain controlling, activities are carried out on more than only one time-horizon.

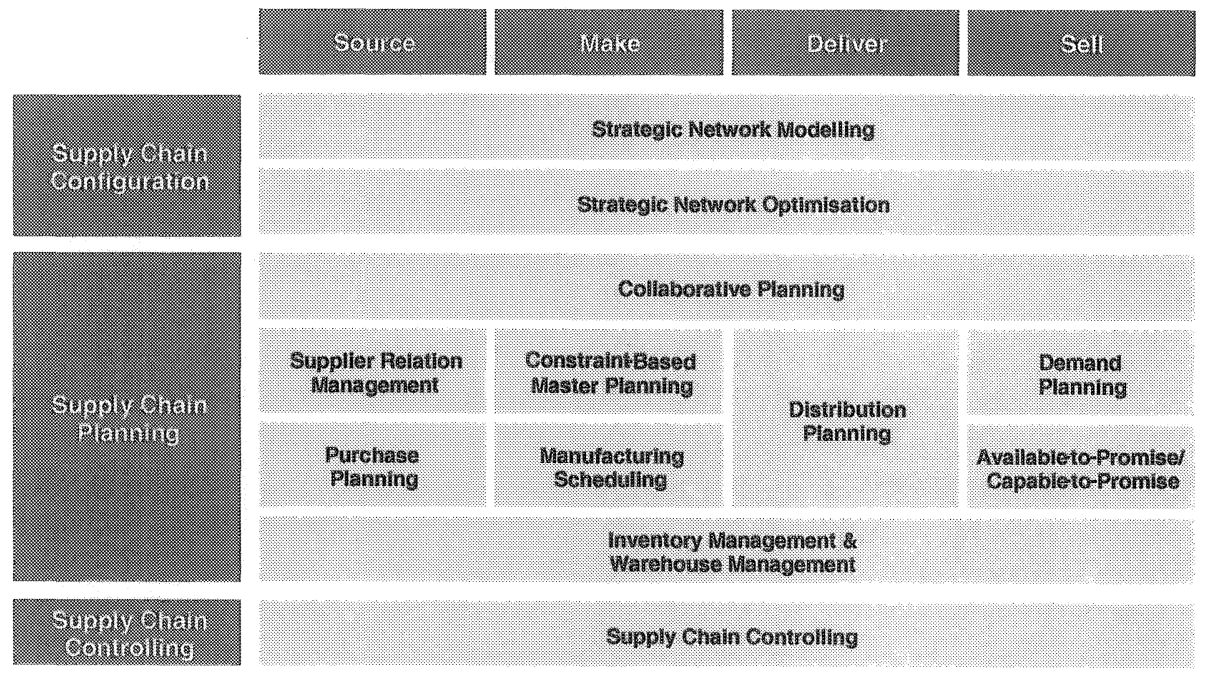

Figure 1 - Planning activities in supply chain management

In the following, the planning levels as well as the planning activities are briefly described. These planning activities relate to the features of current, state-of-the-art SCM systems. 


\section{Supply Chain Configuration}

The purpose on the configuration level is to optimally configure the production and supply network in order to transform a company's long term strategy. To this end, all supply channels from the raw material supplier to the end consumer have to be analysed and modelled on a periodic basis. This is usually done based on yearly demand and production Figures. Besides this rather static view, data concerning capacities and times have to be taken into account, e.g. capacities and lead times of specific production sites. Then what-if scenarios can be generated to simulate the effect of strategic decisions as well as the influence of changing market demands on the overall supply chain performance. Therefore, what-if analyses can be seen as a first step towards a simulative approach to optimise the logistic structure.

\section{Strategic Network Modelling}

The objective of this activity is to generate and model a detailed picture of the supply chain structure and its restrictions. Other than information on capacities and quantities, cost Figures should be incorporated into the model as well, e.g. manufacturing costs, inventory holding costs, and transportation costs.

\section{Strategic Network Optimisation}

Based on the supply chain model obtained in strategic network modelling, one can optimise the overall logistic performance by using sophisticated optimisation algorithms. These algorithms are usually based on linear or mixed linear programming approaches, and, thus, vary by the number of formulated constraints and target variables.

\section{Supply Chain Planning}

Supply chain planning is the coordinated, mid to long-term planning of master production programme across the supply chain. The planning activities ensure that the resources to fulfil the (scheduled) orders are planned optimally. Provided that the supply chain is modelled detailed enough, constraints, e.g. capacities, material, or transportation distances can be considered simultaneously in the plan. The output of planning activities should be a feasible plans to synchronise all source, make, deliver and sell processes along the entire supply chain. The ability to represent interdependencies in the supply chain and to retrieve information about capacity utilisation enables the simulative check of product availability.

\section{Demand Planning}

To some extent, production typically covers an anonymous market demand. In this case, demand planning activities aim at forecasting future expected sales. Various methods are designed to raise the forecast accuracy, e.g. by considering seasonal influence on sales. Additionally, information is structured in various dimensions - e.g. region, product, time - to be aggregated as input for other planning activities. Collaborative forecasts reduce uncertainty using information from 
companies' core divisions, e.g. sales, production, marketing, and procurement, as well as from distribution points and further downstream from the point of sales. For example, sales order information can be transmitted through scanners in real-time to the production plants and made available for demand planning activities.

\section{Collaborative Planning}

Collaborative planning serves for cross-organisational coordination of planning activities of several organisation units. In predefined negotiation procedures, suggestions from one partner may be consented by other partners. Threshold values of tolerance deviations can be taken into account and simplify the negotiation process.

\section{Constraint-based Master planning}

Technological drivers of recent development and implementation of SCMsystems are novel planning approaches summarised under advanced planning and scheduling systems (APS). An APS system overcomes deficits of hierarchical, topdown, MRP-based systems (Materials Requirement Planning) which are based on an iterative planning approach of. In fact, an APS system simultaneously plans all resources (material, due dates, capacities) under consideration of all constraints simultaneously to generate technically feasible master production schedules [7]. With the emergence of APS algorithms, simultaneous planning regarding both material and production resources constraints can be carried out on a mid-term basis and across multiple suppliers, production and distribution sites. In contrast to manufacturing scheduling (see below), which is rather short-term, master planning emphasises the tactical level by optimally allocating orders to resources in the supply network.

\section{Supplier Relation Management and Purchase Planning}

Supplier relation management means to control and execute the process from the ordering request via status query up to issuing an invoice and its settlement, based on internet technologies.

The main tasks of purchase planning is the determination of suppliers as well as the calculation of delivery dates for supplied parts. For an optimal selection of a supplier, all affected cross- and inter-organisational interdependencies must be taken into account. Both, external suppliers and internal warehouses or production sites must be considered. External and internal suppliers have to be compared according to various criteria. For example, the risk of non-compliance is an important criterion in favour or against an external supplier, but no affair at all for evaluation an internal supplier. The choice of a supplier is not determined only by short-term aspects (e.g. today's lowest price). Purchase planning has a strategic, long-term effect.

\section{Distribution Planning}

Based on planning data, received from distribution planning, the carrying out of the transportation planning can be optimised under consideration of cost and delivery date. Furthermore the distribution planning facilitates a need-oriented 
inventory management. Also unexpected shortfalls or cross-border transportation can be taken into account.

\section{Manufacturing Scheduling}

Manufacturing scheduling aims at generating optimised time and sequence schedules for shop floor resources. It is possible to consider set-up times as constraints or simulate diverse heuristic scenarios like priority rules (first-in-firstout, shortest operation time etc.). The operational character of this planning level points at a short time horizon.

\section{Demand Fulfilment}

The integrated view on the complete supply chain allows to immediately react to individual customer requests. One can distinguish between two methods. Available-to-Promise (ATP) queries provide delivery dates based on available inventory. Manufacturing and intermediate products are not taken into account. This procedure may result in non-feasible quotes, because constraints like capacities or material supplies are violated [8]. To avoid this problem, the concept of Capable-toPromise (CTP) is introduced. Here, the whole multi-stage production process is considered. Demand fulfilment activities have an operational character and, thus, pertain to a short time horizon.

\section{Inventory and Warehouse Management}

To achieve low inventory levels and, at the same time, high service levels, integrated inventory and warehouse management along the whole supply chain is necessary. Coordinated, cost-optimised strategies assure economic stock-keeping and distribution by determination of e.g. capacities, safety stocks or vehicle loading.

\section{Supply Chain Controlling}

The continuously increasing market dynamics lead to frequently switching supply chain configurations. Hence, monitoring and controlling the supply chain is necessary for evaluating the existing structure and particularly for anticipating expected configurations. Central issue is the elaboration of a system to measure performance and costs. An actively controlled supply chain needs meaningful ratios, either from cost accounting or from logistics, to reproduce the actual state. A comparison with target ratios, e.g. generated through an analysis of Best-in-Class Figures, may reveal potential of optimisation. SCM relevant ratios were identified and labelled as Key Performance Indicators (KPIs) thus retrieve in the SCORModel [6]. For example the "perfect order fill rate" is reached, when the right product is delivered to the right place at the right time [8]. This KPI is an extensive measure to ensure customer satisfaction at the highest level. The performance of inventory management e.g. can be expressed by ,inventory days of supply“, the mean time in days measured from an imaginary stop of incoming stock to shortage.

In the elaborated model planning activities related to supply chain management are attributed to either the configuration, the planning, or the controlling level. The 
planning activities differ referring to the regarded management process and the time horizon. In following this model serves to structure the SCM-system market.

\section{MARKET SURVEY}

The FIR has been observing and analysing both the SCM-market and the market for Enterprise Resource (ERP) systems for more than ten years. For this survey, which is carried out continuously, the following sources have been systematically evaluated to include as many vendors from the SCM-market in German speaking countries:

Former surveys on SCM-systems,

a Recent consulting projects,

- Visits on tradeshows including the related literature,

- Relevant professional journals and software catalogues,

Internet search.

Finally, data from 35 software vendors and systems were registered [7]. To simplify the data collection process, an internet platform was installed for data collection and administration (www.it-matchmaker.com). To keep the systems' data comparable, answering options were predefined. Furthermore the internet platform offers various and helpful evaluation options. In order to make sure that vendors' statements about their system's software features are reliable, the FIR is executing one-day workshops to verify and confirm information provided by the vendors.

To be able to offer an extensive decision-support tool, information about every listed system is subsumed in one of three parts:

* vendor profile,

- reference projects,

- software features.

The vendor profile provides details about the software company's characteristics, e.g. company history, number of employees, office locations, alliances etc. In part "reference projects" typical reference customers are listed in terms of size, industry, number of production sites or product portfolio. The primary focus, however, is dedicated to the part "software features". There, criteria according to the planning activities (see Figure 1) are listed. The developed criteria catalogue comprises 1320 criteria in total, of which 135 are related to the vendor profile, 284 to reference projects and 901 to software features.

As depicted in Figure 2, an example of a criterion is given. Chapter 10 of the criteria catalogue lists questions about software features concerning demand planning. Question 10.3 in particular deals with scenarios, which may be considered in the forecast methods of SCM-systems. 


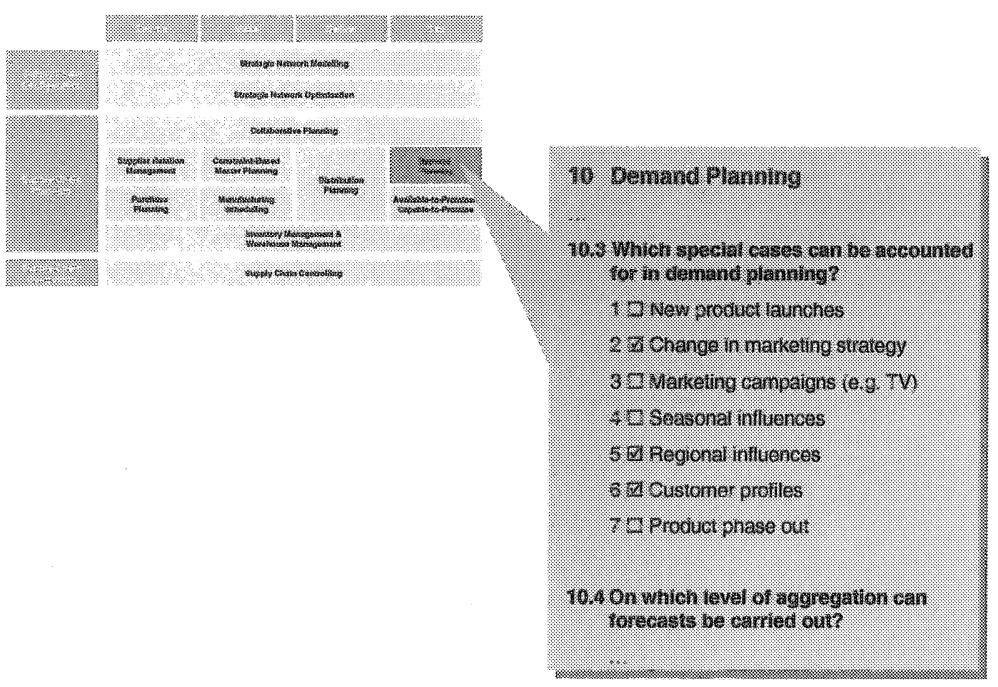

Figure 2 - Example of a criterion from the criteria catalogue

\section{MARKET ANALYSIS}

Analysing the information gained from the survey, one can distinguish between systems types as well as vendor types. The different system types represent the different focus of the systems. This categorization makes it for companies searching for an appropriate SCM system possible to concentrate their selection on tools that accord to their demands. The categorization also structures the complex market of SCM systems. The complexity of the market does not origin from the high amount, but from the very different focuses of the systems.

To illustrate the difference between system types, examples from different industries are given. Implementation focus of systems according to industrial sectors is presented. To demonstrate the results, one example criterion is analysed and a summarising overview of all systems is presented.

\section{Types of Software Systems}

Regarding the software types one can distinguish between:

1. Strategic network planning,

2. Master planning systems,

3. Production scheduling systems,

4. Fulfillment systems.

Strategic network planning (1) systems focus on supply chain configuration. They can be characterised as decision support systems to model the network of procurement, production, distribution and sales for a long term horizon. In a scenario management framework either the performance of existing supply chains or planned 
supply chain options can be measured. Particularly, these tools are suitable for revealing optimisation potential as a preparing step towards SCM-implementation.

Master planning systems (2) represent solutions for the tactical planning, thus, mid-term planning activities. These systems stress the integrative planning of procurement, production, distribution and sales. Main purpose is the synchronisation of demand and supply information to optimise the material flow along the complete supply chain. Usually, a central master planning for all production sites ensures the coordinated material flow. Thus, these systems are typically implemented in complex supply chains with diverse production sites (multi-site planning).

For example, the semiconductor industry has a long and complex supply chain with distributed capabilities [8]. To compensate the uncertainty of future demand, usually costly flexible production sites ensure a high plant utilisation. Semiconductor products are of highest quality and have a very high ratio of value to volume. Consequently, transportation all over the world is economical feasible. These prerequisites demonstrate that flexible and sophisticated procurement is essential. Hence, supply relation management as well as purchase planning are important issues. The existence of a complex network and variable demand requires a coordinated mid-term master planning to optimally allocate the orders to resources.

Production scheduling systems (3) support the assembly line and the shop floor. As decision support systems they complement execution systems such as Enterprise Resource Planning (ERP) systems. To overcome the deficits of traditional material requirement planning (MRP), simultaneous planning of resources - material, time, capacities - consider side conditions such as technological data or employees qualification. The planner is supported by simulative what-if analysis, e.g. when rush orders have to be scheduled. Additionally the planner may favour objectives (e.g. capability utilisation or short lead times) and is in the position to check the consequences of several sequence planning heuristics.

Fulfilment systems (4) combine demand fulfilment activities with those from short-term distribution planning. These systems are implemented as add-ons to ERPsystems (Enterprise Resource Planning). The quality of typical features like Available-to-Promise (ATP) or continuous replenishment (CR) - i.e. automatic shipments when a low stock level is registered at the point of sales - is raised significantly if constraints from the distribution and transportation (e.g. decoupling points, distribution paths, vehicle load capacities, routing) are considered. Recognising a strong interdependency between these short-term-planning activities, this specific system type evolved in recent years.

The food and beverage industry, for example, typically serves an anonymous market [8]. In this case, for example, accurate forecast methods are important to exactly meet future market demand. As food and beverages are perishable and produced in bulk, anticipation of changing demands avoids costs. Thus, real-time transmission of sales data is crucial.

\section{Types of Vendors}

The above mentioned types of software were developed by diverse types of vendors and therefore can be categorised as follows: 
- Vendors of integrated SCM solutions,

- Vendors of niche solutions,

* ERP-vendors.

In the early 90's integrated SCM solutions occurred, typically covering a wide range of the above mentioned planning activities. By means of new planning algorithms, deficits from MRP-logic were eliminated. A modular product portfolio allows a project specific implementation. The clientele is characterised by a large employee number (500+) and complex production structures.

Vendors of niche solutions do not cover all planning activities. They are restricted to one or certain planning activities. Most vendors are small to medium sized and treat industry specific problems, e.g. job floor scheduling. Usually, niche solutions are used as add-ons to ERP-systems. Then, one or more capabilities from the transaction system are replaced by the SCM-module to achieve better planning results. Thus, niche solution traditionally treat a narrow range of use.

ERP-vendors were lastly expanding onto the SCM-market, but have strategic advantages deriving from a long experience in software implementation and a high number of customers. ERP-vendors offer SCM-modules either through proprietary development or by acquisition of SCM-vendors and integration in the own product portfolio.

\section{Industry Focus}

In general, the capability of a SCM-system strongly depends on the regarded industry. Regarding the implemented systems specific industries are stressed. Moreover, from an individual software vendors' point of view, usually specific industrial sectors are favoured. As depicted in Figure 3, one can recognise implementation focus in industries such as automotive, high tech and similar organised sectors. Regarding the individual software vendors separately, high diversification occur due to the above described differentiation of vendor and systems types. 


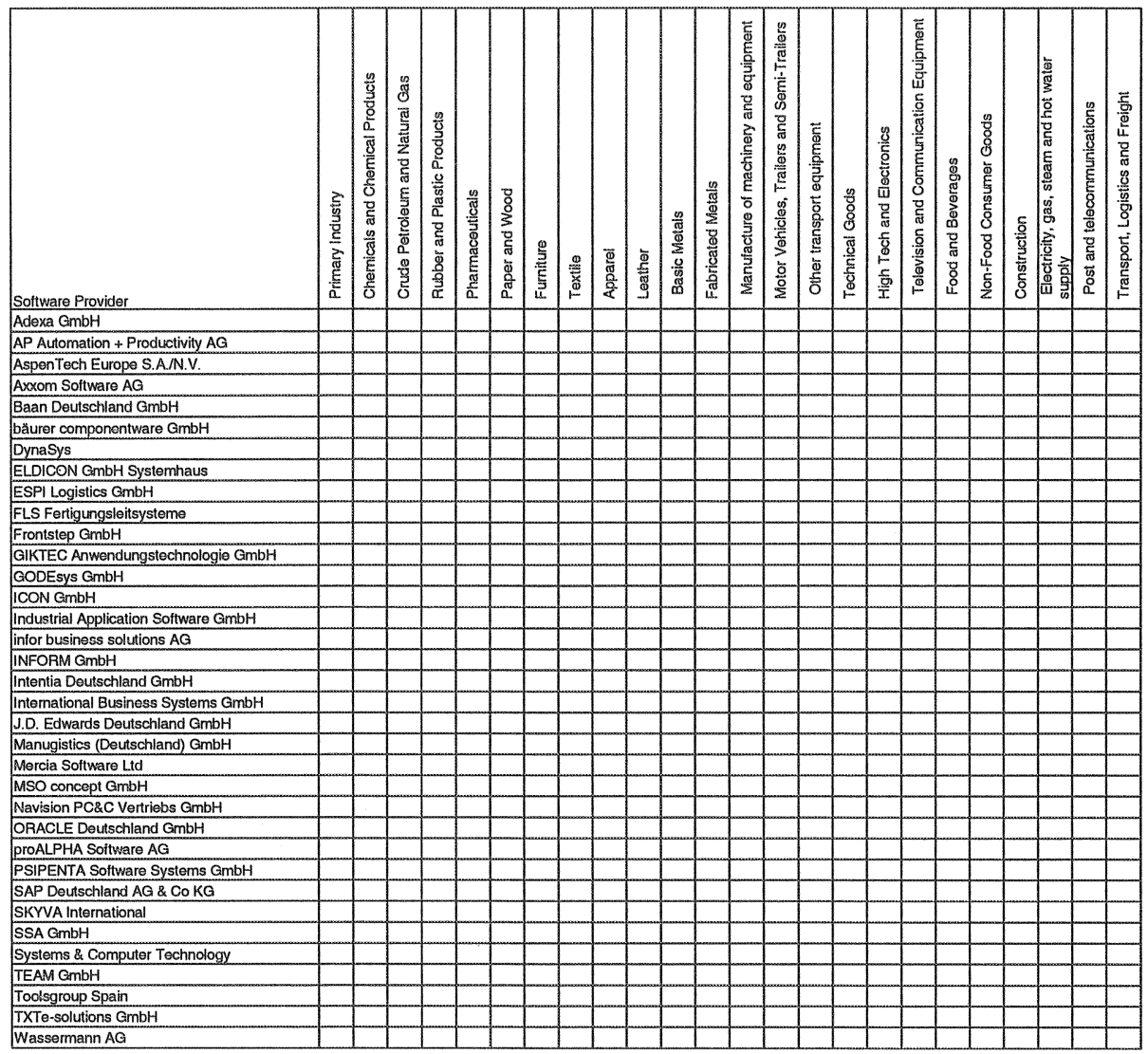

Figure 3 - Reference customers of software providers grouped by industry

\section{Results from Analysis}

The aggregation of criteria to the level of planning activities, leads to the map of performance degrees as depicted in Figure 4. The high limits of variation concerning the fulfilment degree for several planning activities document the differences in emphasis of software systems. 


\begin{tabular}{|c|c|c|c|c|c|c|c|c|c|c|c|}
\hline Software Provider & 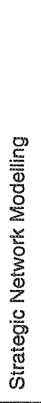 & 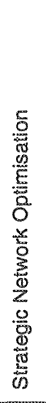 & 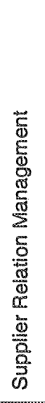 & 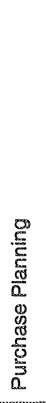 & 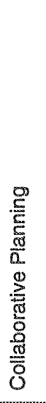 & 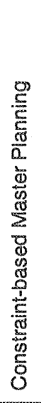 & 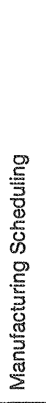 & 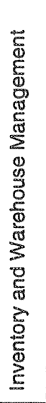 & 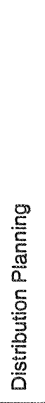 & 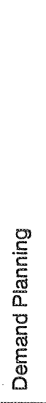 & 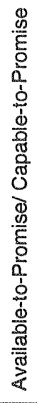 \\
\hline \multicolumn{12}{|l|}{ Adexa GmbH } \\
\hline \multicolumn{12}{|l|}{ AP Automation + Productivity AG } \\
\hline \multicolumn{12}{|l|}{ AspenTech Europe S.A.NN.V. } \\
\hline \multicolumn{12}{|l|}{ Axxom Software AG } \\
\hline \multicolumn{12}{|l|}{ Baan Deutschland GmbH } \\
\hline \multicolumn{12}{|l|}{ bäurer componentware $\mathrm{GmbH}$} \\
\hline DynaSys & - & - & - & & & & & & & & \\
\hline \multicolumn{12}{|l|}{ ELDICON GmbH Systemhaus } \\
\hline ESPI Logistics GmbH & & & - & - & - & - & - & - & - & - & - \\
\hline FLS Fertigungsleitsysteme & & & & - & & & & & & & \\
\hline Frontstep GmbH & & & & & & & & & - & - & \\
\hline \multicolumn{12}{|l|}{ GIKTEC Anwendungstechnologie $\mathrm{GmbH}$} \\
\hline \multicolumn{12}{|l|}{ GODEsys GmbH } \\
\hline \multicolumn{12}{|l|}{ ICON GmbH } \\
\hline \multicolumn{12}{|l|}{ Industrial Application Software GmbH } \\
\hline \multicolumn{12}{|l|}{ infor business solutions $A G$} \\
\hline \multicolumn{12}{|l|}{ INFORM GmbH } \\
\hline \multicolumn{12}{|l|}{ Intentia Deutschland GmbH } \\
\hline International Business Systems (IBS) GmbH & & & & & & - & - & & & & \\
\hline \multicolumn{12}{|l|}{ J.D. Edwards Deutschland GmbH } \\
\hline \multicolumn{12}{|l|}{ Manugistics (Deutschland) GmbH } \\
\hline Mercia Software Ltd & & - & & & & & & & & & \\
\hline MSO concept GmbH & & & & & & & & & & - & \\
\hline \multicolumn{12}{|l|}{ Navision PC\&C Vertriebs GmbH } \\
\hline \multicolumn{12}{|l|}{ ORACLE Deutschland GmbH } \\
\hline proALPHA Software AG & & - & & & & & & & & & \\
\hline \multicolumn{12}{|l|}{ PSIPENTA Software Systems GmbH } \\
\hline \multicolumn{12}{|l|}{ SAP Deutschland AG \& Co KG } \\
\hline SKYVA International & & & & & & & & & & - & \\
\hline \multicolumn{12}{|l|}{ SSA System Software Associates $\mathrm{GmbH}$} \\
\hline Systems \& Computer Technology & & & & & & & & & & - & \\
\hline TEAM GmbH & & & & & & & - & - & - & - & - \\
\hline Toolsgroup Spain & & & & & & - & - & & & & \\
\hline \multicolumn{12}{|l|}{ TXTe-solutions GmbH } \\
\hline Wassermann $A G$ & & & & & & & & & & & \\
\hline
\end{tabular}

Figure 4 - Map of fulfilment degrees aggregated to the planning activities level

\section{FUTURE DEVELOPMENTS}

Both the German as well as the European market for SCM systems are still relatively young [12]. The growth forecasts for this market segment indicate, however, that SCM systems will establish on the market in the medium to long-term future as a systematic complement to existing transaction systems, e.g. ERP systems. 
At present, there are only occasional or hardly any reference projects with a fullbreadth implementation of SCM functionalities. Consequently, the installation of SCM systems still is confining itself to single enterprises, usually large legally coherent conglomerates or supply chains where a focal enterprise plays a dominant role. This corresponds to the predominant philosophy of most SCM systems, particularly master planning systems which pursue a centralist planning approach and assume a central planning authority. The FIR sees an essential development trend of today's SCM systems in the transition of centralist planning approaches to more distributed planning and plan coordination approaches. First attempts to support distributed planning are available, however, there is still largely undeveloped potentials in support of flexible coordination processes [9].

Another essential area of use area of both inter- and cross-organisational workflow management procedures - Supply Chain Event management (SCEM) [11]. SCEM describes the production of process visibility across the entire supply chain. Unplanned and unexpected events can so be detected early and adequate response measures taken. Furthermore events also can be linked to key performance indicators (KPI) so that a flow of information or process is initiated when a certain threshold value of the KPI is reached or surpassed.

Another increase in software functionalities can be expected in the area of distribution and transportation planning. This applies particularly to suppliers of ERP systems who continuously improve their functionalities in the direction of an integrated solution. This view is also shared by Frost \& Sullivan [10] which expect functionalities on the tactical level and on the operational level to merge more and more. Thus, the functional differences between supply chain planning and fulfilment systems will in this respect disappear in the future.

\section{REFERENCES}

[1] H. Luczak: "Supply chain management" in: Lecture Notes on Rationalisation and Reorganisation, FIR Aachen, 1999.

[2] M. Cooper, D. Lambert, and J. Pagh, "Supply chain management: More than a new name for logistics," International Journal of Logistics Management, no. 1, pp. 1 - 13, 1997.

[3] Definition presented at the annual business meeting, Council of Logistics Management, Anaheim, CA, October 1998.

[4] D. Simchi-Levi, P. Kaminsky, and E. Simchi-Levi, "Designing and Managing the Supply Chain: Concepts, Strategies, and Case Studies." Boston: McGraw-Hill Higher Education, 2000.

[5] D. Lambert, M. Cooper, and J. Pagh, "Supply chain management: Implementation issues and research opportunities," International Journal of Logistics Management, no. 2, pp. 1 $-19,1998$.

[6] Supply Chain Council. Supply chain operations reference (SCOR) model, 2002.

[7] P. Schiegg, R. Roesgen, C. Philippson, H. Mittermayer, and R. Kipp. Market Survey Business Software - Supply Chain Management 2002. FIR Aachen, 2002.

[8] H. Stadtler and C. Kilger, editors. Supply Chain Management and Advanced Planning. Springer, Berlin, Heidelberg, New York, 2000.

[9] Bremicker, Helmut ; Lührs, Timo ; Wilke, Jörg ; Diebold Internationale Management und Technologieberatung (Hrsg.): Supply Chain Management - Vision und 
Wirklichkeit. Wien, Zürich, Budapest, Eschborn, Düsseldorf, München : Diebold Internationale Management und Technologieberatung, 2000. - URL http://www.diebold.de/media/pdf/Artikel SCM Tools.pdf

[10] Frost \& Sullivan 2001 Frost \& Sullivan: Europamarkt für Supply Chain Management Software - Frost \& Sullivan Report 3848. Frost \& Sullivan, 2001. - URL http://www.frost.com

[11] K. Knickle, "Supply chain event management - the next best thing to supply chain perfection,", AMR Research, 2001, URL: http://www.amrresearch.com/preview/011029alert652.htm

[12] META Group 2001 META Group: Supply Chain Management und Collaboration in Deutschland - Technologien und Trends für das erweiterte Unternehmen. - URL http://www.metagroup.de/studien/scm2000/, 2001. 